\title{
Biodiesel from "Morelos” Rice: Synthesis, Oxidative Stability, and Corrosivity
}

\author{
J. Zuñiga-Díaz, ${ }^{1,2}$ E. Reyes-Dorantes, ${ }^{1,2}$ A. Quinto-Hernandez $\mathbb{D}^{1},{ }^{1}$ J. Porcayo-Calderon $\left(\mathbb{D},{ }^{2,3}\right.$ \\ J. G. Gonzalez-Rodriguez, ${ }^{3}$ and L. Martinez-Gomez $\mathbb{1}^{2,4}$ \\ ${ }^{1}$ Tecnológico Nacional de México, Instituto Tecnológico de Zacatepec, Calzada Instituto Tecnológico 27, 62780 Zacatepec, MOR, \\ Mexico \\ ${ }^{2}$ Instituto de Ciencias Físicas, Universidad Nacional Autónoma de México, Avenida Universidad s/n, 62210 Cuernavaca, MOR, Mexico \\ ${ }^{3}$ CIICAp, Universidad Autónoma del Estado de Morelos, Avenida Universidad 1001, 62209 Cuernavaca, MOR, Mexico \\ ${ }^{4}$ Corrosion y Protección (CyP), Buffon 46, 11590 Mexico City, Mexico
}

Correspondence should be addressed to J. Porcayo-Calderon; jporcayoc@gmail.com

Received 12 September 2017; Revised 9 December 2017; Accepted 26 December 2017; Published 31 January 2018

Academic Editor: Tingyue Gu

Copyright (C) 2018 J. Zuñiga-Díaz et al. This is an open access article distributed under the Creative Commons Attribution License, which permits unrestricted use, distribution, and reproduction in any medium, provided the original work is properly cited.

Rice bran is a by-product of great production worldwide and its use for the synthesis of biodiesel does not affect the food chain and therefore it is an excellent alternative for the production of biofuels with low carbon footprint. In this work, the synthesis of biodiesel was carried out from the raw rice bran oil of a kernel variety called "Morelos rice." The stability and corrosivity characteristics of biodiesel were determined. Biodiesel stability was determined both under storage conditions and under accelerated oxidation conditions, and its corrosivity was evaluated by electrochemical impedance spectroscopy at $110^{\circ} \mathrm{C}$ under aerated conditions. The results showed that, due to the high instability of the rice bran, its raw oil had a high content of free fatty acids. The synthesized biodiesel showed excellent stability under storage conditions of up to five months, and its oxidative stability was much higher than that established in international standards. On the other hand, biodiesel showed low corrosivity and this was only significant once oxidative degradation began.

\section{Introduction}

The environmental impact caused by the use of fossil fuels has motivated the need to search for other sustainable sources of energy. In this sense, biofuels such as biodiesel are an interesting alternative to partially or totally replace the consumption of mineral diesel. Vegetable oils are the main raw material for biodiesel production, and they are a renewable and environmentally friendly source that helps reduce the $\mathrm{CO}_{2}$ emissions; this is because the plants from which the oil is obtained use the anthropogenic $\mathrm{CO}_{2}$ for their growth [1-3].

The term biodiesel has been used to define the monoalkyl esters of long chain fatty acids derived from renewable lipids such as vegetable oils or animal fats [4], which are nontoxic and biodegradable, contain oxygen in their molecules, and are free of sulfur and carcinogenic compounds; therefore, biodiesel is a cleaner fuel than gasoline and diesel [5]. The energy extracted during the biodiesel combustion actually comes from the sun through the photosynthetic activities of the plants. Plants are one of the biotic forms with the shortest time of fixation of anthropogenic $\mathrm{CO}_{2}$, so the use of biodiesel reduces the emissions of greenhouse gases [6,7].

There is a strong controversy both in the use of edible oils and in the cultivation of nonedible oil sources in order to synthesize biodiesel. Current efforts should be directed to those sources of vegetable oil that do not affect, directly or indirectly, the food chain. In addition, the cost of edible oils as a raw material for biodiesel synthesis represents a high percentage (up to 50\%) of the overall synthesis process $[6,8,9]$. Therefore, the current vision should focus on the use of agricultural by-products or agroindustrial waste that does not affect the food chain. A clear example is the use of rice bran. Rice bran is a by-product of the paddy grain 
milling process. Rice bran constitutes about $10 \%$ by weight of the kernel and contains a good amount of oil [10].

The oil content of the rice bran can be as high as $25 \%$ depending on the milling process, geographical origin, and the rice grain variety $[11,12]$. However, because of its high free fatty acid content, rice bran oil has little application as edible oil [13-15]. Almost all rice bran produced in the world is discarded or used as a cheap raw material for animal feed and as boiler fuel; this is due to the action of the enzyme lipase which is released during its production and which causes the rancidity of its oil in a short time [9, 11-18]. Rice is one of the most consumed cereals in the world and, therefore, produces important by-products such as rice bran $[9,13]$. The use of this by-product does not affect the food chain, and due to its high production, it is a sustainable source of low cost products for the generation of new products with higher added value and low carbon footprint.The quality of both the rice bran and its oil depends on the variety of the rice kernel. In this study, biodiesel has been synthesized from the rice bran of the "Morelos rice" which is a variety of rice with high oil content grown exclusively in Morelos state, Mexico. The stability of biodiesel has been evaluated under longterm storage conditions. Moreover, the oxidative stability and the corrosivity of biodiesel have been investigated by electrochemical techniques.

\section{Experimental Procedure}

2.1. Biodiesel Synthesis. Biodiesel was synthesized from raw rice bran oil (RRBO). The rice bran was collected shortly after its production in a local mill (Puente de Ixtla, Morelos, Mexico). For the extraction of its oil, the rice bran was dried at $70^{\circ} \mathrm{C}$ until the elimination of its moisture. The rice bran used is a by-product of the "Morelos" rice with certificate of denomination of origin. Morelos rice is considered one of the best quality rice products at the international level [19], as the main characteristic of "Morelos" rice is that it is an extra-large opaque grain which is cultivated exclusively in Morelos state (Mexico)

RRBO extraction was carried out with hexane at room temperature using a flour-solvent ratio of $1: 10$. The chemical (fatty acids) and physicochemical (density, acid index, iodine index, peroxide index, and saponification index) characteristics of the RRBO were determined by gas chromatography and according to AOAC methods 920.21, 940.28, 920.158, 965.33, and 920.160, respectively.

The synthesis of biodiesel was carried out as described by Lin et al. [8]. The synthesis process was monitored by gas chromatography and by FTIR spectroscopy. The process was carried out in two stages. In the first one, the esterification of the free fatty acids was carried out, and in the second one the transesterification of the triglycerides. For the esterification of the free fatty acids (FFA), a methanolic solution of sulfuric acid (1wt.\%) was added to molar ratio of 1:7 (free fatty acids: methanolic solution). The esterification process was carried out at reflux for 1 hour with constant stirring at $65^{\circ} \mathrm{C}$. By means of thin layer chromatography (TLC), the disappearance of the free fatty acids is verified. Subsequently,

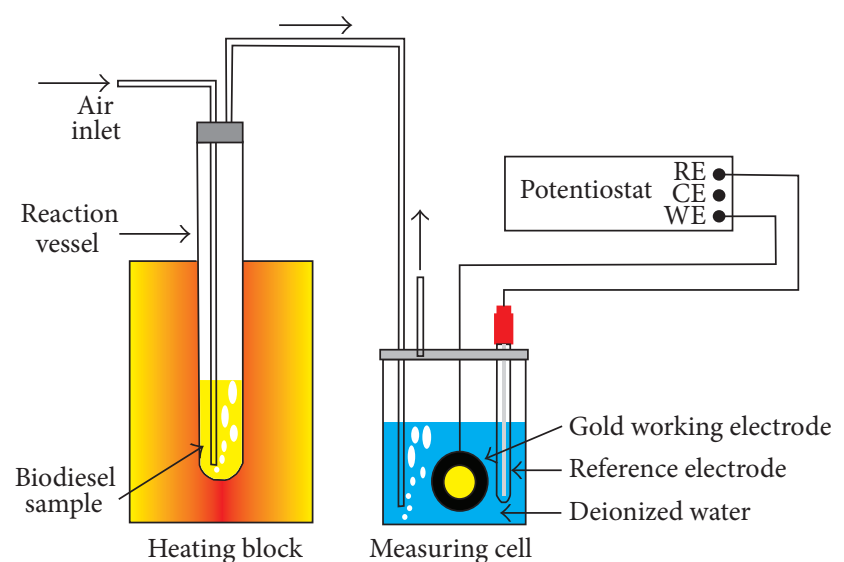

FIGURE 1: Scheme of the experimental arrangement used to determine the oxidative stability of biodiesel based on OCP measurements.

methanol is removed by evaporation, and the sulfuric acid is removed by centrifugation. The resulting product is subjected to the transesterification of the triglycerides by the addition of a $\mathrm{KOH}$ methanolic solution $(0.9 \% \mathrm{w} / \mathrm{w})$ in a ratio of $1: 10$ (triglycerides : methanolic solution). The mixture is heated to $70^{\circ} \mathrm{C}$ with constant agitation and the course of the transesterification reaction is monitored by TLC until complete conversion of the triglycerides to methyl esters. After the transesterification process, methanol is removed by evaporation and glycerol is separated by centrifugation. The biodiesel is washed with distilled water until obtaining a neutral $\mathrm{pH}$, and later it is dried with $\mathrm{Na}_{2} \mathrm{SO}_{4}$. Chemical and physicochemical characterization of the biodiesel was performed in a similar way to the raw oil.

2.2. Biodiesel Stability. Determination of biodiesel stability was carried out considering storage conditions (room temperature and sunlight absence) for 6 months. The monitoring of biodiesel stability was performed by the evolution of its physicochemical parameters.

The oxidative stability of biodiesel was performed by a new method based on the measurement of the open circuit potential (OCP) between a gold working electrode and deionized water, similar to the resistivity measurement used in the so-called Rancimat method as illustrated in Figure 1 [13-15]. The OCP between a working electrode and the deionized water will remain stable as long as the chemical composition of the electrolyte remains unchanged. However, because the air stream injected into the biodiesel is subsequently bubbled into the deionized water, both the chemical composition and the conductivity of the electrolyte can change due to the dissolution of the volatile oxidation products in addition to the $\mathrm{CO}_{2}$ and $\mathrm{O}_{2}$ of the air. Because of this, OCP measurements can be useful in determining the oxidative stability of biodiesel. Time-dependent OCP measurements between the gold working electrode and a saturated calomel electrode (SCE) were carried out with an ACM Instruments Zero potentiometer coupled to a personal computer. The oxidative stability of biodiesel was determined 
at 80,110 , and $140^{\circ} \mathrm{C}$ using an air flow of $10 \mathrm{l} / \mathrm{h}$. Before each test and in the absence of air bubbling, the OCP was measured for one hour and air bubbling in the biodiesel was then initiated.

2.3. Biodiesel Corrosivity. The corrosivity of the biodiesel was evaluated by electrochemical impedance spectroscopy (EIS) on 304 stainless steel (SS). A three-electrode electrochemical cell was used, where the 304 SS is the working electrode (WE), a platinum mesh is the counter electrode (CE), and a platinum wire is the reference electrode (RE). The CE and RE were located at a distance of $0.5 \mathrm{~mm}$ from the WE reaction area. The corrosivity tests were carried out at $110^{\circ} \mathrm{C}$ with continuous bubbling of air at $10 \mathrm{l} / \mathrm{h}$. These conditions guarantee the absence of humidity of the biodiesel and, therefore, the observed corrosivity will correspond exclusively to its oxidation products. Once the test temperature was reached, the electrode array was introduced into the biodiesel and after 15 minutes of stabilization the EIS measurements were initiated. EIS measurements were carried out at OCP in a frequency interval of $100 \mathrm{kHz}$ to $0.1 \mathrm{~Hz}$ using sinusoidal perturbation amplitude of $50 \mathrm{mV}$. Because in highly resistive systems (thick paints, oils, and biodiesel) it is extremely difficult to make EIS measurements, in this work, it was chosen to work with a perturbation amplitude of $50 \mathrm{mV}$ and a very small separation distance between the electrodes in order to obtain reliable EIS spectra [20-22]. A Gamry Interface 1000 potentiostat/galvanostat controlled by a personal computer was used for the EIS measurements. Prior to the corrosion tests, the working electrode was polished successively with $\mathrm{SiC}$ papers from grade 120 to 1200 and then washed with distilled water, ethanol, and acetone. The obtained spectra were fitted with the ZView software.

\section{Results and Discussion}

3.1. Biodiesel Synthesis. The raw material (rice bran) had a moisture and oil content of $6.77 \%$ and $21.44 \%$, respectively. The oil content is consistent with the information reported in the literature $[11,23]$. The physicochemical parameters of the raw oil are shown in Table 1 . The average molecular weight of the oil was $923 \mathrm{~g} / \mathrm{gmol}$ and its FFA content was $8.15 \%$. These values are within the range reported for oils extracted from the same source $[8,9,23-25]$. The determined FFA content was high for the oil obtained shortly after the rice bran was produced. This value was due to the activity of the lipase enzyme released during the rice grain milling process [9], in addition to limiting its use for food purposes [25]. Because a percentage of acidity less than $5 \%$ is recommended for the transesterification process of the triglycerides [26], it was therefore necessary to first carry out the esterification step of the FFA. Chromatographic analysis indicated that the RRBO had a content of palmitic acid (C16:0) of 14.54\%, linoleic acid (C18:2) of $35.26 \%$, and oleic acid (C18:1) of $48.48 \%$. The composition was similar to that reported in the literature for this type of oil $[7,8,11,18,27,28]$.

Due to the high FFA content of the oil, the synthesis of the biodiesel was carried out in two stages: FFA esterification
TABLE 1: Physicochemical parameters of the raw rice bran oil.

\begin{tabular}{lc}
\hline Parameter & Amount \\
\hline Density $\left(\mathrm{g} / \mathrm{cm}^{3}\right)$ & 0.877 \\
Saponification index $(\mathrm{mg} \mathrm{KOH} / \mathrm{g})$ & 188.68 \\
Acidity index $(\mathrm{mg} \mathrm{KOH} / \mathrm{g})$ & 0.491 \\
Iodine index $\left(\mathrm{g} \mathrm{I}_{2} / 100 \mathrm{~g}\right)$ & 90.08 \\
Peroxide index $\left(\mathrm{meq}_{2} / \mathrm{kg}\right)$ & 0.83 \\
FFA (\%) & 0.246 \\
\hline
\end{tabular}

and triglycerides transesterification. Figure 2 shows the FTIR spectra of the esterification reaction of the FFA. FTIR spectra have been used to identify the functional groups and bands corresponding to various stretching and flexion vibrations during the synthesis of the biodiesel [29]. FTIR spectrum (Figure 2(a)) was similar to those spectra reported for edible rice bran oil [30]; the main difference is a small signal around $1712 \mathrm{~cm}^{-1}$ which was associated with the carbonyl peak of FFA; this signal appears along with the acylglyceride carbonyl peak $(\mathrm{C}=\mathrm{O})$ at $1743 \mathrm{~cm}^{-1}$ [31]. In oils with high FFA content, the signal $\left(1712 \mathrm{~cm}^{-1}\right)$ is lengthened and there is a shrinking of the corresponding signal to the acylglyceride carbonyl peak $(\mathrm{C}=\mathrm{O})$ [30]. After the esterification process, the disappearance of this signal was evident (Figure 2(b)). This indicates the conversion of the FFA to their respective methyl esters. Other additional common signals can be observed in both spectra [32-37]. Around $3500 \mathrm{~cm}^{-1}$, a broad $-\mathrm{OH}$ stretching vibration peak is observed. At $3007 \mathrm{~cm}^{-1}$, the stretching vibration of the cis $(=\mathrm{C}-\mathrm{H})$ double bonds from the oleic and linoleic fatty acids is observed. At $2922 \mathrm{~cm}^{-1}$ and $2853 \mathrm{~cm}^{-1}$, the asymmetric and symmetrical stretching vibrations of the $-\mathrm{CH}_{2}$, respectively, are observed. At $1461 \mathrm{~cm}^{-1}$, the flexural vibrations of the $-\mathrm{CH}_{2}$ are observed, as well as the flexural vibrations of the $-\mathrm{CH}_{3}$ at $1375 \mathrm{~cm}^{-1}$. At $721 \mathrm{~cm}^{-1}$, the characteristic peak of chains with more than four $-\mathrm{CH}_{2}$ groups and the flexion vibration outside the plane of the cisbond $(-\mathrm{HC}=\mathrm{CH}-)$ associated with the alkyl chain of oleic and linoleic acid are observed. At 1238 and $1163 \mathrm{~cm}^{-1}$, the signal of the symmetrical stretch and asymmetric stretching of the $-\mathrm{C}-\mathrm{O}$ is observed. Some authors assign the band at $1238 \mathrm{~cm}^{-1}$ to the flexion vibration outside the plane of the methylene group [34]. Table 2 summarizes the main groups identified in the FTIR spectra.

Figure 3 shows the FTIR spectra of the transesterification reaction of the triglycerides. Due to the structural similarity between the triglycerides of the oil and the methyl esters of biodiesel, the spectra of both are very similar [37]. Thereby, the signals described in Figure 2 are the same as those observed in Figure 3. However, the absence of two important signals should be distinguished to ensure the purity of the synthesized biodiesel, namely, the signal associated with the carbonyl peak of the FFA (around $1712 \mathrm{~cm}^{-1}$ ) which indicates that the first stage of the synthesis process was performed successfully and the absence of a broad absorption band $\left(3300-2500 \mathrm{~cm}^{-1}\right)$ indicating the absence of moisture as a result of an efficient biodiesel purification process [31, 37]. 


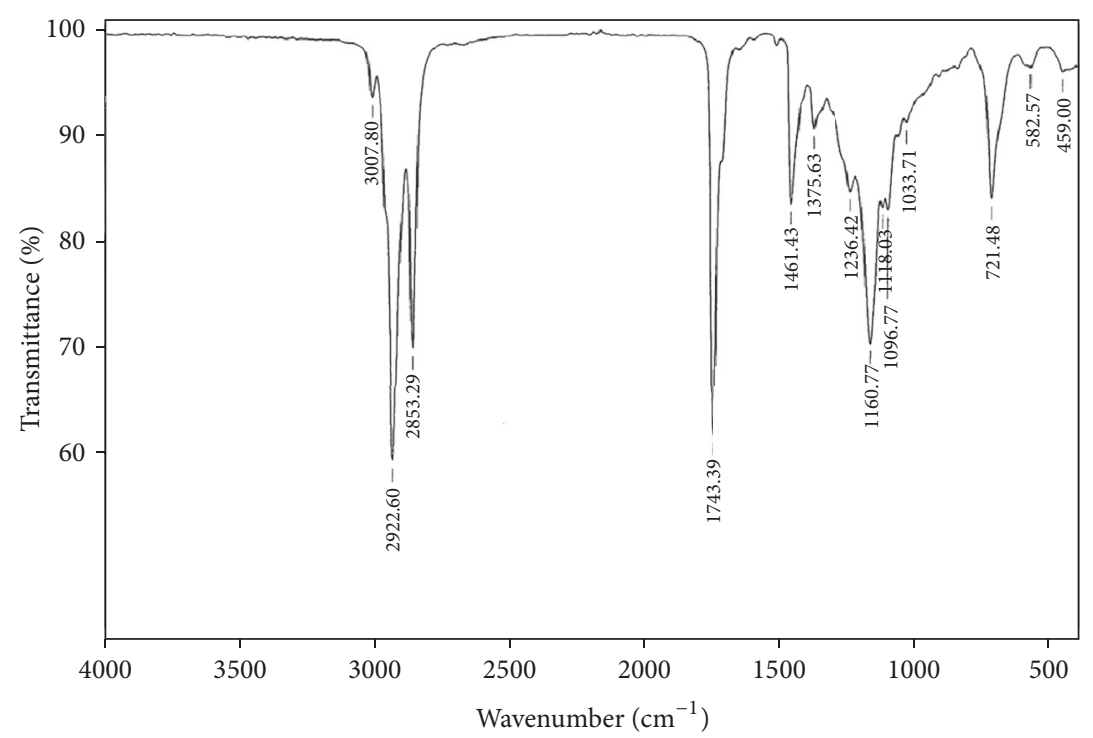

(a)

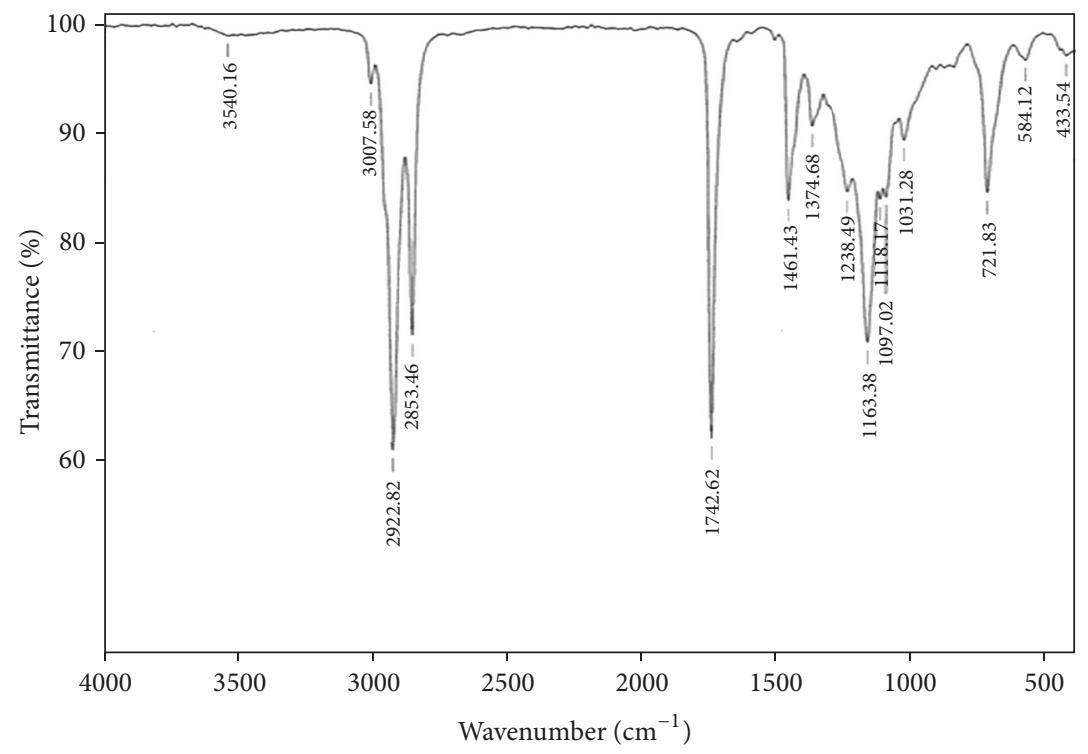

(b)

FIGURE 2: FTIR spectra of the esterification process: (a) $t=0 \mathrm{~min}$ and (b) $t=60 \mathrm{~min}$.

The elimination of impurities (moisture, residual catalyst) is essential both to define the quality and stability of the synthesized biodiesel and to prevent detrimental effects on combustion engines [7, 38]. As can be seen from Figure 3(b), the synthesized biodiesel complies with both concepts.

Physicochemical characterization of the synthesized biodiesel is shown in Table 3 at different storage times. According to the values shown, it is possible to observe that there was a reduction both in the density, as in the acidity index and the peroxide index, and in the FFA content with respect to those values reported for the oil (see Table 1). These changes were due to the process of esterification and transesterification of the oil. The determined parameters are within the limits established by ASTM D6751 [39], EN 14214 [39], and DIN V51606 [24].
3.2. Biodiesel Stability. The evolution of the physicochemical parameters of biodiesel is shown in Table 3. In general, it can be observed that during the storage period no significant variation of the monitored parameters was observed. However, it can be observed that the acidity index increased slightly with respect to time, and after 5 months it was slightly above the limit established by international standards $(0.5 \mathrm{mg} \mathrm{KOH} / \mathrm{g})$ $[24,39]$. A high acidity index of biodiesel can cause problems due to the formation of deposits in the fuel system (pumps and filters). There was also a slight decrease in the iodine index value as a consequence of the oxidation of the double bonds present in the hydrocarbon chains resulting in the formation of peroxides as reaction products; this parameter is of great importance in the synthesis of biofuels because high values of this index indicate a low stability of the 


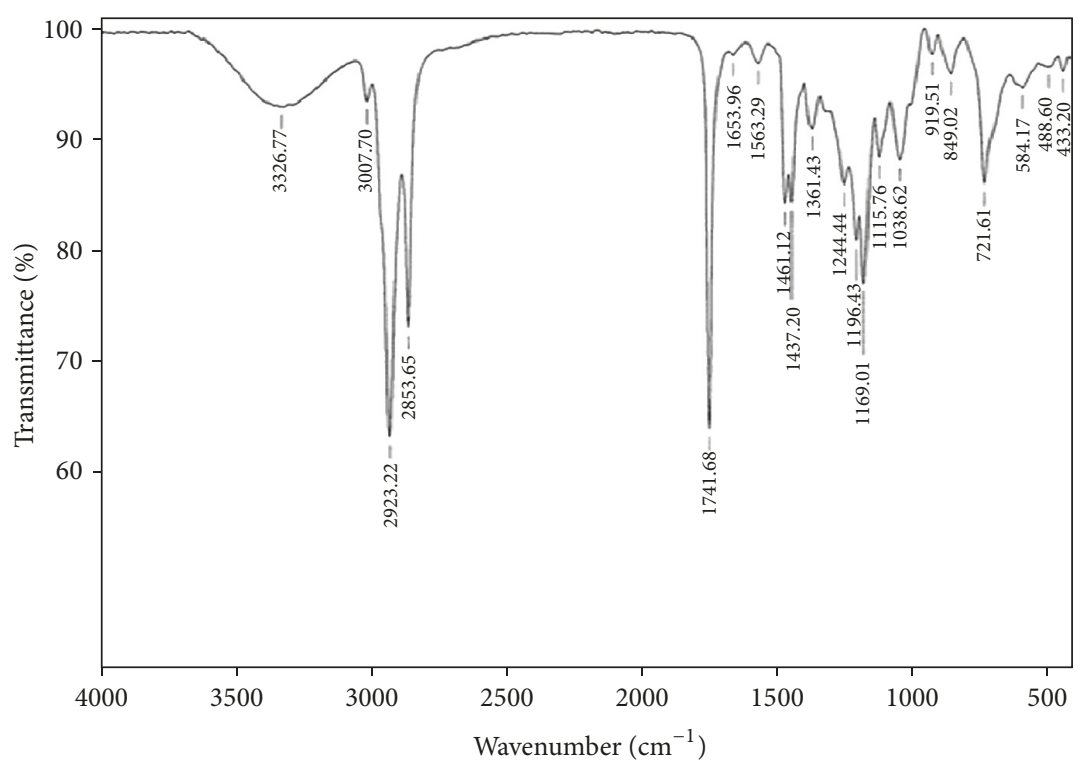

(a)

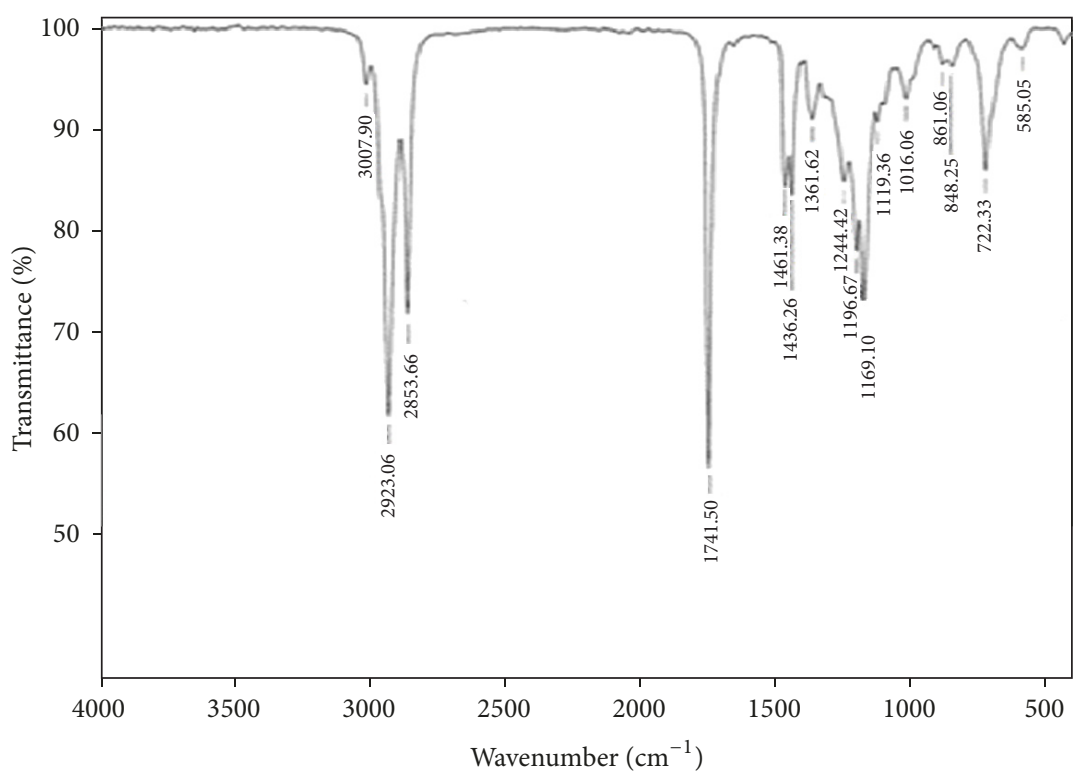

(b)

FIgURE 3: FTIR spectra of the transesterification process: (a) $t=20 \mathrm{~min}$ and (b) purified biodiesel after $120 \mathrm{~min}$ of reaction.

biofuel [40]; however, the values are within the established international standards. Due to the oxidation of the double bonds of the hydrocarbon chains, the values of the peroxide index tended to increase with respect to the storage time. Although this parameter is important because high values of the peroxide index can favor the formation of solids and the deterioration of the oil lubricant [40], the international standards do not take it into account within the quality criteria of biodiesel. However, because the peroxide index is related to the iodine index, it can be said that the value obtained is acceptable. According to the evolution of the physicochemical parameters of the biodiesel derived from RRBO, it can be said that, under storage conditions, it showed an excellent stability up to the fifth month according to the limits allowed in the ASTM D6751 [39], EN 14214 [39], and DIN V51606 [24] standards. Its only critical parameter is the acidity index which could be stabilized by the addition of antioxidants.

3.3. Biodiesel Oxidative Stability. Because biodiesel is susceptible to degradation either by autoxidation or by photooxidation, determining its stability is an important factor. The biodiesel degradation can occur by oxidation under aerobic conditions, hydrolysis in the presence of moisture, thermal decomposition by excess heat, contamination of impurities, and so forth. The products of its degradation (acids, aldehydes, esters, ketones, peroxides, alcohols, and polymers) can cause the formation of precipitates and their darkening 


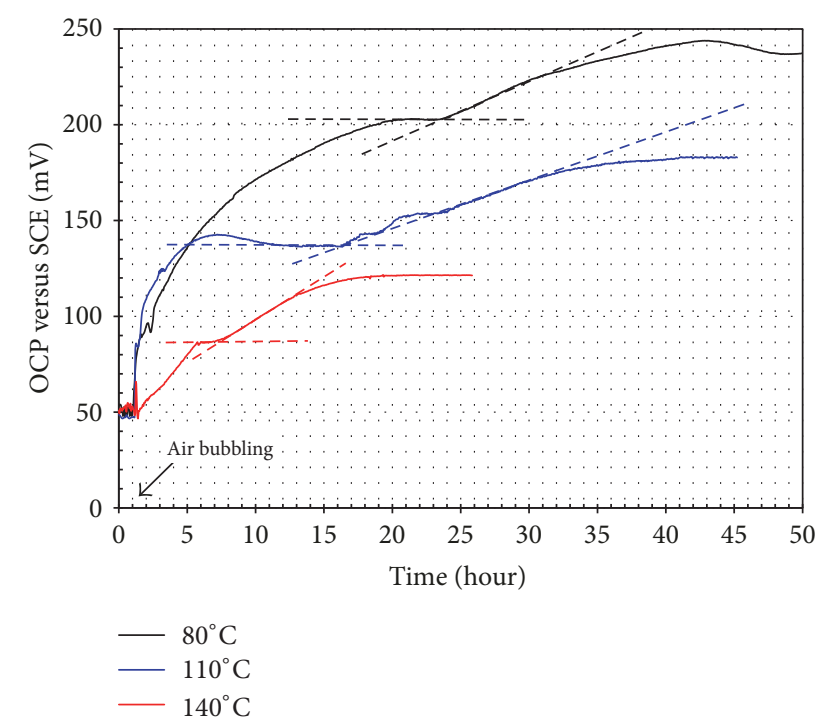

FIGURE 4: Evolution of OCP measurements during the biodiesel oxidation at different temperatures.

TABLE 2: Main groups identified in the FTIR spectra.

\begin{tabular}{lcc}
\hline Wavenumber $\left(\mathrm{cm}^{-1}\right)$ & Group & Reference \\
\hline 721 & $-\mathrm{CH}_{2}$ & {$[32-37]$} \\
1163 & $-\mathrm{C}-\mathrm{O}$ & {$[32-37]$} \\
1238 & $-\mathrm{HC}=\mathrm{CH}-$ & {$[32-37]$} \\
1238 & $\mathrm{H}_{2} \mathrm{C}=$ & {$[34]$} \\
1375 & $-\mathrm{CH}_{3}$ & {$[32-37]$} \\
1461 & $-\mathrm{CH}_{2}$ & {$[32-37]$} \\
1712 & $=\mathrm{C}=\mathrm{O}_{0}$ of FFA & {$[30]$} \\
1743 & $=\mathrm{C}=\mathrm{O}$ of acylglyceride & {$[30]$} \\
2853 & $-\mathrm{CH}_{2}$ & {$[32-37]$} \\
2922 & $-\mathrm{CH}$ & {$[32-37]$} \\
3007 & $=\mathrm{C}-\mathrm{H}$ & {$[32-37]$} \\
3500 & $-\mathrm{OH}$ & {$[32-37]$} \\
\hline
\end{tabular}

$[14,15]$. Usually, the oxidative stability of biodiesel is evaluated by the so-called Rancimat method [13-15], a conductometric method where biodiesel is subjected to accelerated oxidation conditions. In short, the biodiesel is usually heated at $110^{\circ} \mathrm{C}$, and either air or oxygen $(10-201 / h)$ is bubbled through it. These test conditions accelerate the biodiesel degradation and the oxidation products are collected in deionized water. Therefore, the conductivity of deionized water will tend to increase, and the time at which this occurs is defined as the biodiesel stability time. Therefore, based on the Rancimat method, in this work, the conductivity meter was replaced by an arrangement of two electrodes in order to determine the variation of the OCP of the gold WE with respect to SCE as a function of time. Figure 4 shows the OCP measurements evolution as time elapsed for biodiesel at different temperatures. In general, it is observed that the OCP curves showed the evolution of two slopes and two apparent plateaus. The evolution of the first slope can be associated with dissolved gases (adsorption of $\mathrm{CO}_{2}$ and $\mathrm{O}_{2}$ mainly) due to the air bubbling, and the second slope can correspond to the dissolution of the biodiesel oxidation products. In both cases, the plateaus correspond to the saturation of the deionized water due to both $\mathrm{CO}_{2}$ and $\mathrm{O}_{2}$ absorption and the oxidation products dissolution, respectively. Then, the interception of the tangent of the first plateau with the tangent of the second slope corresponds to the stability time of the biodiesel [41]. According to this, it can be observed that the oxidative stability of biodiesel was 23.6, 16.2, and 7.3 hours at 80,110 , and $140^{\circ} \mathrm{C}$, respectively. According to European standard EN 14112, it has been established that the induction time accepted as a measure of the oxidative stability of biodiesel should be at least 6 hours at $110^{\circ} \mathrm{C}$. The excellent oxidative stability observed can be attributed to the particular characteristics of the source oil, namely, the presence of natural antioxidants [42], and its low content of methyl ester of linoleic acid (C18:2), since it has been reported that its oxidation rate is 12 times higher than that of methyl ester of oleic acid (C18:1) [43].

The RRBO has the highest saturated to unsaturated fatty acid ratio and a high content of natural antioxidants as compared to refined or dewaxed/degummed oil. Both wax esters and phospholipids (3-4\%) and an important fraction of the unsaponifiable matter (5\%) such as $\gamma$-oryzanol, tocopherols, tocotrienols, phytosterols, and steryl esters are removed during refining or dewaxing/degumming of the raw oil $[20,44,45]$. In addition, it has been observed that, during the biodiesel synthesis process, the unsaponifiable matter remains in the final product [44], thus favoring the presence of antioxidants in the biodiesel. In particular, tocopherols have shown a high stability at a temperature of $100^{\circ} \mathrm{C}$ for more than 400 hours [46]. These characteristics favor the excellent oxidative stability of biodiesel synthesized from the crude oil of rice bran.

However, although biodiesel may contain antioxidants from the source oil, one of the main factors that directly affect its stability is the presence of double bonds in the fatty acids of the constituent methyl esters. In general, the hydrogen atoms of both the allylic and the bisallylic positions are the starting points for the oxidative degradation of biodiesel $[14,15]$. Therefore, since polyunsaturated methyl esters are more susceptible to oxidation than monounsaturated methyl esters, and monounsaturated methyl esters are more susceptible than saturated methyl esters, it is possible that the degradation of the RRBO started with the allylic and bisallylic positions of the methyl ester of linoleic acid.

3.4. Biodiesel Corrosivity. Biodiesel shows a tendency to absorb moisture due to the hygroscopic character of the esters that make it up. Moisture (water) tends to condense on the metal surfaces that contain it and causes their deterioration due to metallic corrosion. In addition, the reaction products of the biodiesel oxidation process (aldehydes, ketones, lactones, and organic acid compounds) considerably increase the biodiesel's corrosivity [41,47]. The corrosivity of biodiesel on different metallic materials has been evaluated both by electrochemical techniques and by mass loss tests. However, due to the high resistivity of biodiesel, in many studies, a second electrolyte (e.g., water) is added in order to increase 

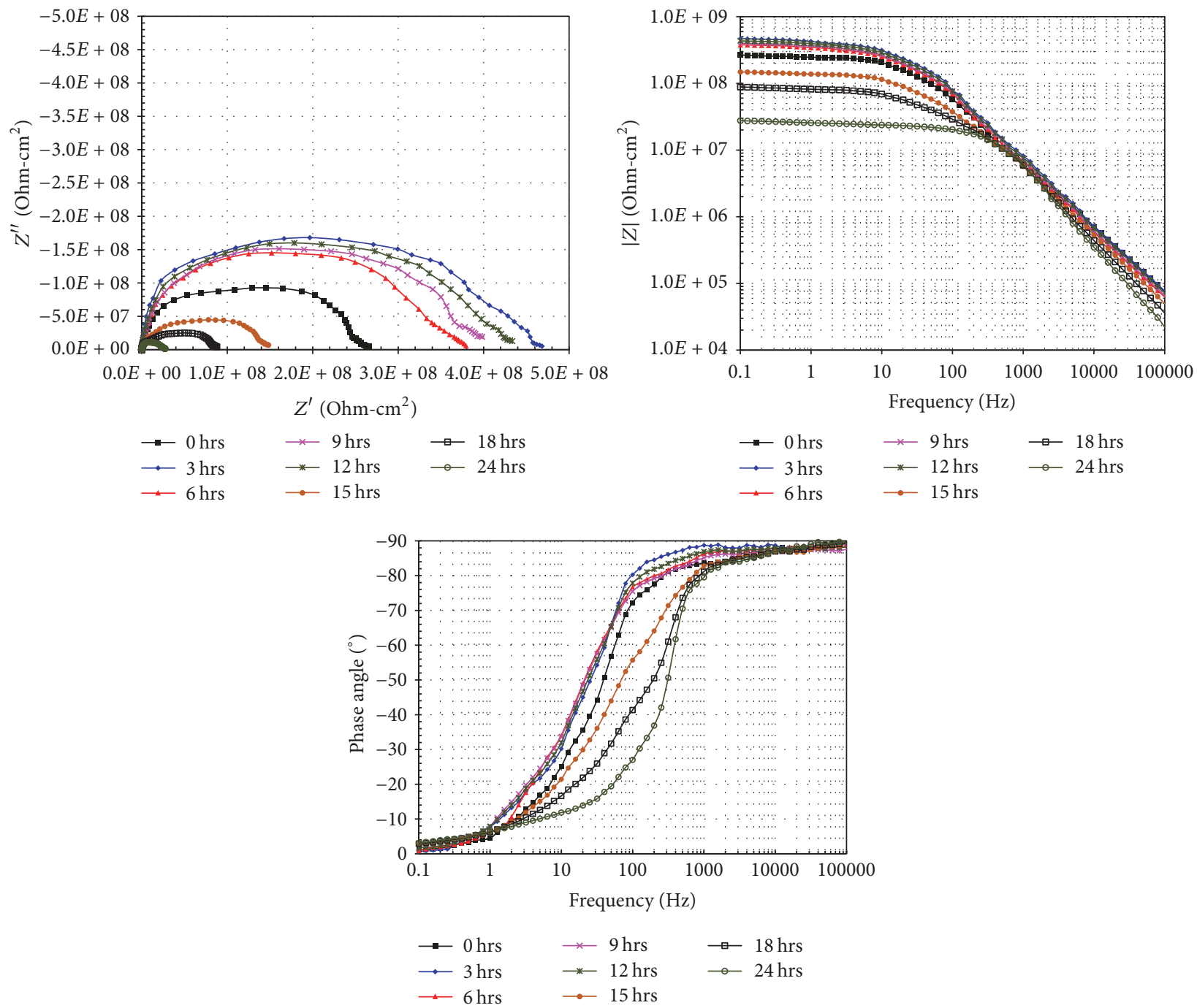

FIgUre 5: Nyquist and Bode plots for 304 stainless steel evaluated in biodiesel at $110^{\circ} \mathrm{C}$.

TABLE 3: The physicochemical parameters of biodiesel after different storage times.

\begin{tabular}{|c|c|c|c|c|c|c|c|}
\hline Month & 0 & 1 & 2 & 3 & 4 & 5 & 6 \\
\hline Density $\left(\mathrm{g} / \mathrm{cm}^{3}\right)$ & 0.877 & 0.875 & 0.880 & 0.881 & 0.881 & 0.880 & 0.880 \\
\hline Saponification index $(\mathrm{mg} \mathrm{KOH} / \mathrm{g})$ & 188.68 & 184.51 & 194.15 & 181.71 & 182.01 & 181.74 & 181.14 \\
\hline Acidity index (mg KOH/g) & 0.491 & 0.455 & 0.480 & 0.482 & 0.494 & 0.572 & 0.664 \\
\hline Iodine index $\left(\mathrm{g} \mathrm{I}_{2} / 100 \mathrm{~g}\right)$ & 90.08 & 85.18 & 86.08 & 87.89 & 82.01 & 83.23 & 81.36 \\
\hline Peroxide index $\left(\right.$ meq $\left.\mathrm{O}_{2} / \mathrm{kg}\right)$ & 0.83 & 1.20 & 5.35 & 6.58 & 6.88 & 7.54 & 8.36 \\
\hline FFA $(\%)$ & 0.246 & 0.228 & 0.241 & 0.242 & 0.248 & 0.287 & 0.333 \\
\hline
\end{tabular}

its conductivity and thus its corrosivity [20, 47-53]. Because many corrosion tests are conducted at temperatures where the degradation rate of biodiesel is slow, the exposure times may be up to months in order to obtain reliable corrosion measurements. Therefore, the corrosivity studies reported here were carried out at $110^{\circ} \mathrm{C}$ and with air bubbling at $10 \mathrm{l} / \mathrm{h}$.

Figure 5 shows the impedance spectra obtained over 24 hours of testing. It should be noted that the measurement corresponding to "zero" time was performed in the absence of air bubbling. From the Nyquist diagram, it is possible

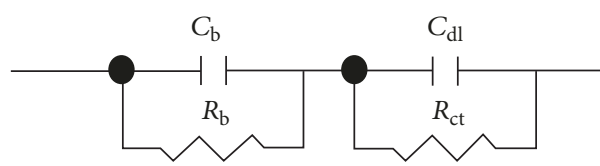

FIGURE 6: Equivalent circuit used to model the impedance spectra.

to observe the apparent presence of a single capacitive semicircle, which can be attributed to the response of the electrochemical double layer [20]. However, due to the high 

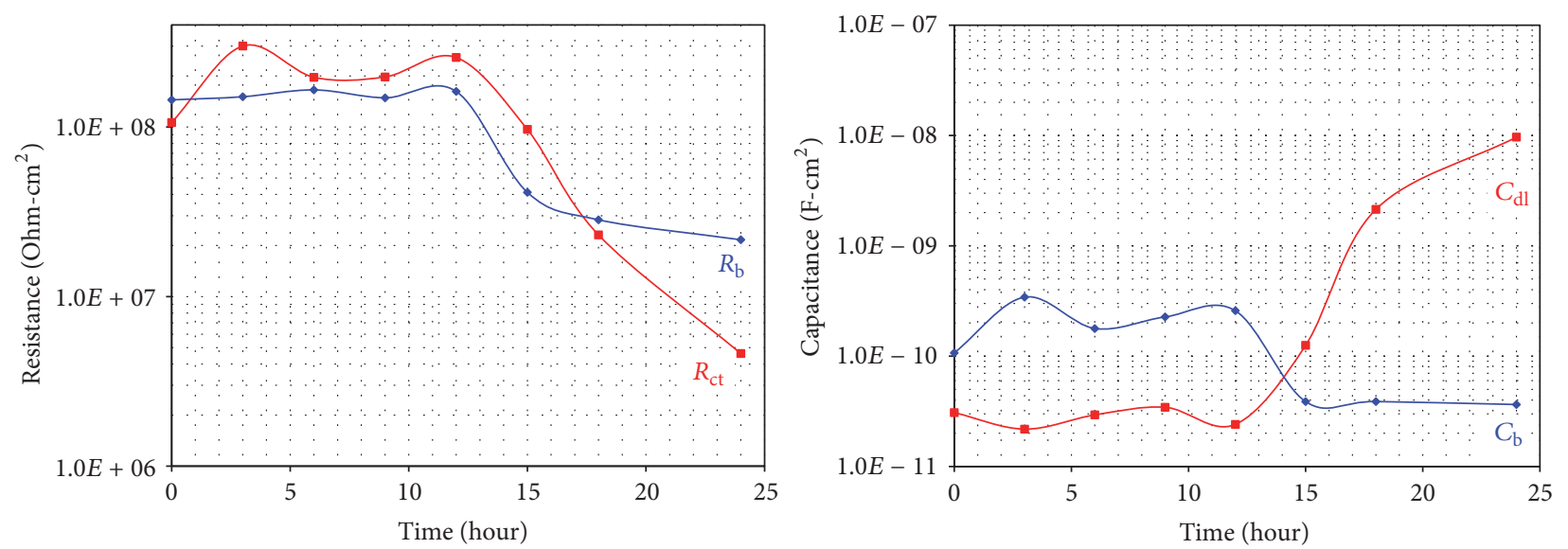

FIGURE 7: Electrochemical parameters extracted from the impedance spectra.

resistivity of biodiesel, it is not obvious to associate such response with the corrosion processes at the metal-electrolyte interface [20]. However, despite this, the analysis of the Bode diagram can differentiate the capacitive response of biodiesel from the response of the stainless steel corrosion process [5458]. From the phase angle spectrum, it is possible to observe only part of the characteristic shape (Gauss bell shape) of the phase angle corresponding to one single time constant. However, the width of this time constant suggests that there are actually two overlapping time constants which evolve from the high frequency region to the intermediate frequency region; something similar has been reported when an oily film is adsorbed by the metal surface $[54-57,59]$. Therefore, the response observed in the region of high frequency $(>1000 \mathrm{~Hz}$, phase angle maximum practically constant and close to $90^{\circ}$ ) represents the capacitive response of biodiesel, and that observed in the intermediate frequency region $(10-1000 \mathrm{~Hz}$, phase angle maximum variable) is due to the corrosion process in the steel-biodiesel interface [60]. From the impedance modulus plot in the low frequency region, the presence of a plateau is observed, and its evolution indicates the variation of the corrosion resistance of stainless steel as time elapses. It is interesting to note that once the air was bubbled in the biodiesel, the impedance module increased immediately; this can be associated with the formation of a passive layer on the stainless steel due to the oxidation process of its surface. However, at greater times than 12 hours, the impedance modulus decreased drastically due to the corrosion process caused by the oxidation products of the biodiesel. This is in agreement with the results of oxidative stability of biodiesel, which indicated an induction time of 16.2 hours at $110^{\circ} \mathrm{C}$.

Based on the above, the electrochemical response of the system could be modeled by an electric circuit consisting of two parallel circuits (capacitance-resistance) connected in series (Figure 6). In this equivalent circuit, the first circuit represents the dielectric response of the biodiesel with capacitance $C_{\mathrm{b}}$ (electrical dissipation) and resistance $R_{\mathrm{b}}$ (resistivity), and the second circuit represents the corrosion process occurring at the steel-biodiesel interface with capacitance of the double layer electrochemical $C_{\mathrm{dl}}$ and resistance to the transfer of charge $R_{\mathrm{ct}}$.

Assuming this model, Figure 7 shows the evolution of the electrochemical parameters obtained from the impedance spectra. It can be observed that the $R_{\mathrm{ct}}$ values are very big for times lower than 18 hours, and these decreased by two orders of magnitude due to an increase in the biodiesel corrosivity. A similar trend is observed in the $R_{\mathrm{b}}$ values; at times less than 15 hours, the values were practically constant, and at higher times a drop in the $R_{\mathrm{b}}$ values was observed due to the degradation of biodiesel. At the same time, the $C_{\mathrm{dl}}$ values showed an inverse behavior; that is, the values were small for low corrosion rates and increased up to three orders of magnitude by increasing the corrosion rate of stainless steel. It can be observed that the capacitance values $\left(C_{\mathrm{b}}, C_{\mathrm{dl}}\right)$ are extremely small but congruent for highly resistive electrolytes, such as biodiesel, and for materials with high corrosion resistance in moisture-free electrolytes [20$22,58]$.

\section{Conclusions}

The use of agroindustrial by-products is an excellent source for the synthesis of biodiesel with low carbon footprint. Due to the low stability of the rice bran, its raw oil contains a high amount of free fatty acids. For this reason, the synthesis of the biodiesel was carried out in two stages, namely, an esterification process of the free fatty acids and a subsequent transesterification process of the triglycerides. The physicochemical parameters determined for biodiesel meet the requirements of international standards. Under long-term storage conditions, biodiesel showed excellent stability up to five months of storage; at longer storage times, it shows a slight increase in its acidity index. The oxidative stability of biodiesel was determined by a similar method to the Rancimat method, using a two-electrode arrangement to determine the variation of the open circuit potential between the gold working electrode and the SCE. The proposed method indicated that biodiesel has an excellent oxidative stability; the values obtained were 23.6, 16.2, and 7.3 hours 
at 80,110 , and $140^{\circ} \mathrm{C}$, respectively. The corrosion tests of biodiesel showed that its corrosiveness is only significant once the oxidation products of biodiesel are formed.

\section{Conflicts of Interest}

The authors declare that there are no conflicts of interest regarding the publication of this paper.

\section{Acknowledgments}

Financial support from Consejo Nacional de Ciencia y Tecnología (CONACYT, Mexico) (Project 159898) is gratefully acknowledged. J. Zuñiga-Díaz and E. Reyes-Dorantes would like to thank the National Council for Science and Technology (CONACYT, Mexico) for the financial support given to realize their postgraduate studies.

\section{References}

[1] M. Fatih Demirbas, "Biorefineries for biofuel upgrading: a critical review," Applied Energy, vol. 86, no. 1, pp. S151-S161, 2009.

[2] A. Demirbas, "Biorefineries: current activities and future developments," Energy Conversion and Management, vol. 50, no. 11, pp. 2782-2801, 2009.

[3] S. N. Naik, V. V. Goud, P. K. Rout, and A. K. Dalai, "Production of first and second generation biofuels: a comprehensive review," Renewable \& Sustainable Energy Reviews, vol. 14, no. 2, pp. 578-597, 2010.

[4] G. Knothe, "Structure indices in FA chemistry. How relevant is the iodine value?" Journal of the American Oil Chemists' Society, vol. 79, no. 9, pp. 847-854, 2002.

[5] A. Demirbas, "Comparison of transesterification methods for production of biodiesel from vegetable oils and fats," Energy Conversion and Management, vol. 49, no. 1, pp. 125-130, 2008.

[6] W. Y. Cheah, T. C. Ling, J. C. Juan, D.-J. Lee, J.-S. Chang, and P. L. Show, "Biorefineries of carbon dioxide: From carbon capture and storage (CCS) to bioenergies production," Bioresource Technology, vol. 215, pp. 346-356, 2016.

[7] S. Sinha, A. K. Agarwal, and S. Garg, "Biodiesel development from rice bran oil: transesterification process optimization and fuel characterization," Energy Conversion and Management, vol. 49, no. 5, pp. 1248-1257, 2008.

[8] L. Lin, D. Ying, S. Chaitep, and S. Vittayapadung, "Biodiesel production from crude rice bran oil and properties as fuel," Applied Energy, vol. 86, no. 5, pp. 681-688, 2009.

[9] J. Yi-Hsu and S. R. Vali, "Rice bran oil as a potential resource for biodiesel: a review," Journal of Scientific and Industrial Research, vol. 64, pp. 866-882, 2005.

[10] M. D. S. Oliveira, V. Feddern, L. Kupski, E. P. Cipolatti, E. Badiale-Furlong, and L. A. De Souza-Soares, "Changes in lipid, fatty acids and phospholipids composition of whole rice bran after solid-state fungal fermentation," Bioresource Technology, vol. 102, no. 17, pp. 8335-8338, 2011.

[11] K. Gul, B. Yousuf, A. K. Singh, P. Singh, and A. A. Wani, "Rice bran: nutritional values and its emerging potential for development of functional food-a review," Bioactive Carbohydrates and Dietary Fibre, vol. 6, no. 1, pp. 24-30, 2015.
[12] S. Bhosale and D. Vijayakshmi, "Processing and nutritional composition of rice bran," Current Research in Nutrition and Food Science, vol. 3, pp. 74-80, 2015.

[13] N. El Boulifi, A. Bouaid, M. Martinez, and J. Aracil, "Optimization and oxidative stability of biodiesel production from rice bran oil," Journal of Renewable Energy, vol. 53, pp. 141-147, 2013.

[14] Z. Yaakob, B. N. Narayanan, S. Padikkaparambil, S. K. Unni, and M. P. Akbar, "A review on the oxidation stability of biodiesel," Renewable \& Sustainable Energy Reviews, vol. 35, pp. 136-153, 2014.

[15] S. Jain and M. P. Sharma, "Review of different test methods for the evaluation of stability of biodiesel," Renewable \& Sustainable Energy Reviews, vol. 14, no. 7, pp. 1937-1947, 2010.

[16] N. R. Lakkakula, M. Lima, and T. Walker, "Rice bran stabilization and rice bran oil extraction using ohmic heating," Bioresource Technology, vol. 92, no. 2, pp. 157-161, 2004.

[17] A. Proctor and D. J. Bowen, "Ambient-temperature extraction of rice bran oil with hexane and isopropanol," Journal of the American Oil Chemists' Society, vol. 73, no. 6, pp. 811-813, 1996.

[18] B. M. W. P. K. Amarasinghe and N. C. Gangodavilage, "Rice bran oil extraction in Sri Lanka data for process equipment design," Food and Bioproducts Processing, vol. 82, no. 1, pp. 5459, 2004.

[19] J. M. Tolentino-Martínez, "The rice production of the state of Morelos under the approach SIAL," Estudios Sociales (Hermosillo, Son.), vol. 22, no. 44, pp. 39-61, 2014.

[20] J. A. Calderon, L. M. Baena, and J. Lenis, "Possibilities of corrosion assessment of metals in biodiesel using EIS," CT\& FCiencia, Tecnología y Futuro, vol. 5, pp. 85-96, 2014.

[21] I.-J. Park, T.-H. Nam, J.-H. Kim, and J.-G. Kim, "Evaluation of corrosion characteristics of aluminum alloys in the bioethanol gasoline blended fuel by 2-electrode electrochemical impedance spectroscopy," Fuel, vol. 126, pp. 26-31, 2014.

[22] J.-C. M'Peko, D. L. S. Reis, J. E. De Souza, and A. R. L. Caires, "Evaluation of the dielectric properties of biodiesel fuels produced from different vegetable oil feedstocks through electrochemical impedance spectroscopy," International Journal of Hydrogen Energy, vol. 38, no. 22, pp. 9355-9359, 2013.

[23] S. Sayasoonthorn, S. Kaewrueng, and P. Patharasathapornkul, "Rice bran oil extraction by screw press method: optimum operating settings, oil extraction level and press cake appearance," Rice Science, vol. 19, no. 1, pp. 75-78, 2012.

[24] A. Srivastava and R. Prasad, "Triglycerides-based diesel fuels," Renewable \& Sustainable Energy Reviews, vol. 4, no. 2, pp. 111133, 2000.

[25] S. Y. Al-Okbi, N. M. Ammar, D. A. Mohamed et al., "Egyptian rice bran oil: chemical analysis of the main phytochemicals," RISG Rivista Italiana Sostanze Grasse, vol. 91, no. 1, pp. 47-58, 2014.

[26] J. Van Gerpen, "Biodiesel processing and production," Fuel Processing Technology, vol. 86, no. 10, pp. 1097-1107, 2005.

[27] E. L. Bakota, J. K. Winkler-Moser, H.-S. Hwang, M. J. Bowman, D. E. Palmquist, and S. X. Liu, "Solvent fractionation of rice bran oil to produce a spreadable rice bran product," European Journal of Lipid Science and Technology, vol. 115, no. 8, pp. 847-857, 2013.

[28] A. G. Gopala Krishna, P. A. Prashanth, A. Pragasam, K. V. Raghavendra, and S. Khatoon, "Unsaponifiable matter and oxidative stability of commercially produced Indian rice bran oils," Journal of Food Lipids, vol. 10, no. 4, pp. 329-340, 2003.

[29] M. Tariq, S. Ali, F. Ahmad et al., "Identification, FT-IR, NMR $\left({ }^{1} \mathrm{H}\right.$ and $\left.{ }^{13} \mathrm{C}\right)$ and $\mathrm{GC} / \mathrm{MS}$ studies of fatty acid methyl esters in 
biodiesel from rocket seed oil," Fuel Processing Technology, vol. 92, no. 3, pp. 336-341, 2011.

[30] A. Rohman, Y. B. C. Man, and S. Riyanto, "Authentication analysis of red fruit (pandanus conoideus lam) oil using FTIR spectroscopy in combination with chemometrics," Phytochemical Analysis, vol. 22, no. 5, pp. 462-467, 2011.

[31] S. Özgül-Yücel and A. Proctor, "Rice bran FFA determination by diffuse reflectance IR spectroscopy," Journal of the American Oil Chemists' Society, vol. 81, no. 3, pp. 221-224, 2004.

[32] W. Thongchai and B. Liawruangrath, "Determination of gamma oryzanol in rice bran oil by HPLC with molecularly imprinted solid-phase extraction," International Food Research Journal, vol. 23, no. 4, pp. 1389-1395, 2016.

[33] I. Hanno, M. Centini, C. Anselmi, and C. Bibiani, "Green cosmetic surfactant from rice: characterization and application," Cosmetics, vol. 2, pp. 322-341, 2015.

[34] M. Safar, D. Bertrand, P. Robert, M. F. Devaux, and C. Genot, "Characterization of edible oils, butters and margarines by Fourier transform infrared spectroscopy with attenuated total reflectance," Journal of the American Oil Chemists' Society, vol. 71, no. 4, pp. 371-377, 1994.

[35] G. Bianchi, O. W. Howarth, C. J. Sameul, and G. Vlahov, "Longrange $\sigma$-inductive interactions through saturated $\mathrm{C}-\mathrm{C}$ bonds in polymethylene chains," Journal of the Chemical Society, Perkin Transactions, vol. 2, pp. 1427-1432, 1995.

[36] I. P. Soares, T. F. Rezende, R. C. Silva, E. V. R. Castro, and I. C. P. Fortes, "Multivariate calibration by variable selection for blends of raw soybean oil/biodiesel from different sources using Fourier transform infrared spectroscopy (FTIR) spectra data," ENERGY \& FUELS, vol. 22, no. 3, pp. 2079-2083, 2008.

[37] J. P. C. Evangelista, T. Chellappa, A. C. F. Coriolano, V. J. Fernandes Jr., L. D. Souza, and A. S. Araujo, "Synthesis of alumina impregnated with potassium iodide catalyst for biodiesel production from rice bran oil," Fuel Processing Technology, vol. 104, pp. 90-95, 2012.

[38] A. S. M. A. Haseeb, M. A. Fazal, M. I. Jahirul, and H. H. Masjuki, "Compatibility of automotive materials in biodiesel: a review," Fuel, vol. 90, no. 3, pp. 922-931, 2011.

[39] G. Knothe, "Analyzing biodiesel: standards and other methods," Journal of the American Oil Chemists' Society, vol. 83, no. 10, pp. 823-833, 2006.

[40] J. M. Encinar, J. F. González, and A. Rodríguez-Reinares, "Biodiesel from used frying oil. Variables affecting the yields and characteristics of the biodiesel," Industrial \& Engineering Chemistry Research, vol. 44, no. 15, pp. 5491-5499, 2005.

[41] J. Zúñiga-Diaz, E. Reyes-Dorantes, A. Quinto-Hernandez, J. Porcayo-Calderon, J. G. Gonzalez-Rodriguez, and L. MartinezGomez, "Oil extraction from 'morelos rice' bran: kinetics and raw oil stability," Journal of Chemistry, vol. 2017, Article ID 3837506, 9 pages, 2017.

[42] E. Sendzikiene, V. Makareviciene, and P. Janulis, "Oxidation stability of biodiesel fuel produced from fatty wastes," Polish Journal of Environmental Studies, vol. 14, no. 3, pp. 335-339, 2005.

[43] S. S. Pantoja, L. R. V. Da Conceição, C. E. F. Da Costa, J. R. Zamian, and G. N. Da Rocha Filho, "Oxidative stability of biodiesels produced from vegetable oils having different degrees of unsaturation," Energy Conversion and Management, vol. 74, pp. 293-298, 2013.

[44] S. Zullaikah, C.-C. Lai, S. R. Vali, and Y.-H. Ju, "A two-step acidcatalyzed process for the production of biodiesel from rice bran oil," Bioresource Technology, vol. 96, no. 17, pp. 1889-1896, 2005.
[45] N. S. Kasim, T.-H. Tsai, S. Gunawan, and Y.-H. Ju, "Biodiesel production from rice bran oil and supercritical methanol," Bioresource Technology, vol. 100, no. 8, pp. 2399-2403, 2009.

[46] A. G. Gopala Krishna, S. Khatoon, P. M. Shiela, C. V. Sarmandal, T. N. Indira, and A. Mishra, "Effect of refining of crude rice bran oil on the retention of oryzanol in the refined oil," Journal of the American Oil Chemists' Society, vol. 78, no. 2, article no. 232, pp. 127-131, 2001.

[47] M. H. Bruscatto, R. C. Zambiazi, M. Sganzerla et al., "Degradation of tocopherols in rice bran oil submitted to heating at different temperatures," Journal of Chromatographic Science, vol. 47, no. 9, pp. 762-765, 2009.

[48] M. A. Fazal, A. S. M. A. Haseeb, and H. H. Masjuki, "Biodiesel feasibility study: an evaluation of material compatibility; performance; emission and engine durability," Renewable \& Sustainable Energy Reviews, vol. 15, no. 2, pp. 1314-1324, 2011.

[49] M. A. Fazal, A. S. M. A. Haseeb, and H. H. Masjuki, "Effect of temperature on the corrosion behavior of mild steel upon exposure to palm biodiesel," Energy, vol. 36, no. 5, pp. 33283334, 2011.

[50] M. A. Fazal, A. S. M. A. Haseeb, and H. H. Masjuki, "Effect of different corrosion inhibitors on the corrosion of cast iron in palm biodiesel," Fuel Processing Technology, vol. 92, no. 11, pp. 2154-2159, 2011.

[51] M. A. Fazal, A. S. M. A. Haseeb, and H. H. Masjuki, "Comparative corrosive characteristics of petroleum diesel and palm biodiesel for automotive materials," Fuel Processing Technology, vol. 91, no. 10, pp. 1308-1315, 2010.

[52] A. S. M. A. Haseeb, H. H. Masjuki, L. J. Ann, and M. A. Fazal, "Corrosion characteristics of copper and leaded bronze in palm biodiesel," Fuel Processing Technology, vol. 91, no. 3, pp. 329-334, 2010.

[53] L. Díaz-Ballote, J. F. López-Sansores, L. Maldonado-López, and L. F. Garfias-Mesias, "Corrosion behavior of aluminum exposed to a biodiesel," Electrochemistry Communications, vol. 11, no. 1, pp. 41-44, 2009.

[54] J. Porcayo-Calderon, M. Casales-Diaz, L. M. Rivera-Grau, D. M. Ortega-Toledo, J. A. Ascencio-Gutierrez, and L. MartinezGomez, "Effect of the diesel, inhibitor and $\mathrm{CO}_{2}$ additions on the corrosion performance of 1018 carbon steel in $3 \% \mathrm{NaCl}$ solution," Journal of Chemistry, vol. 2014, Article ID 940579, 10 pages, 2014.

[55] J. Porcayo-Calderon, I. Regla, E. Vazquez-Velez et al., "Effect of the unsaturation of the hydrocarbon chain of fatty-amides on the $\mathrm{CO}_{2}$-corrosion of carbon steel using EIS and realtime corrosion measurement," Journal of Spectroscopy, vol. 2015, Article ID 184140, 10 pages, 2015.

[56] S. Godavarthi, J. Porcayo-Calderon, M. Casales-Diaz, E. Vazquez-Velez, A. Neri, and L. Martinez-Gomez, "Electrochemical analysis and quantum chemistry of castor oil-based corrosion inhibitors," Current Analytical Chemistry, vol. 12, pp. 476-488, 2016.

[57] J. Porcayo-Calderon, E. M. Rivera-Muñoz, C. Peza-Ledesma et al., "Sustainable development of palm oil: synthesis and electro-chemical performance of corrosion inhibitors," Journal of Electrochemical Science and Technology, vol. 8, pp. 133-145, 2017.

[58] A. Y. Musa, R. T. T. Jalgham, and A. B. Mohamad, "Molecular dynamic and quantum chemical calculations for phthalazine derivatives as corrosion inhibitors of mild steel in $1 \mathrm{M} \mathrm{HCl,"}$ Corrosion Science, vol. 56, pp. 176-183, 2012. 
[59] L. M. Rivera-Grau, M. Casales, I. Regla et al., "Effect of organic corrosion inhibitors on the corrosion performance of 1018 carbon steel in $3 \% \mathrm{NaCl}$ solution," International Journal of Electrochemical Science, vol. 8, no. 2, pp. 2491-2503, 2013.

[60] W. B. Wan Nik, S. Syahrullail, R. Rosliza, M. M. Rahman, and M. F. R. Zulkifli, "Corrosion behaviour of aluminium alloy in palm oil methyl ester (B100)," Jurnal Teknologi, vol. 58, no. 2, pp. 73-76, 2012. 

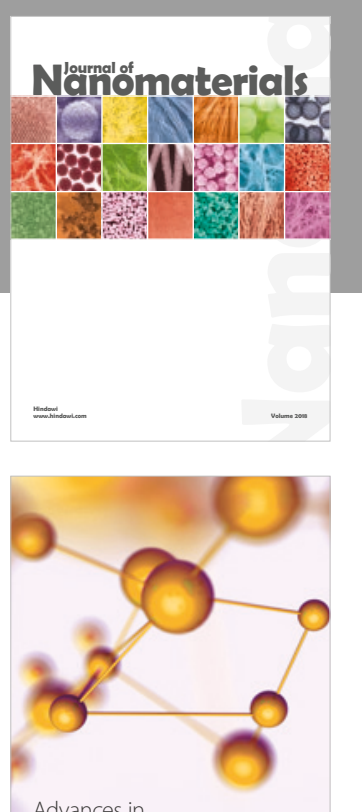

Physical Chemistry
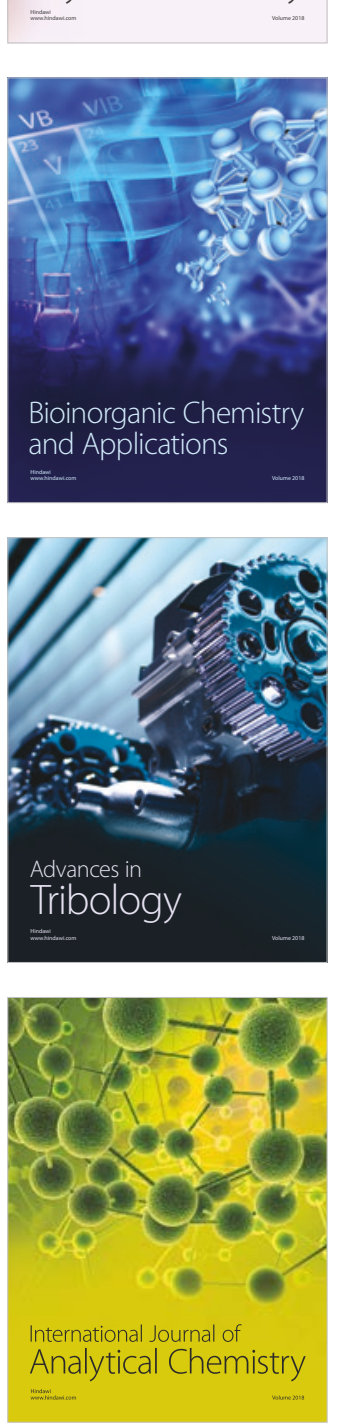

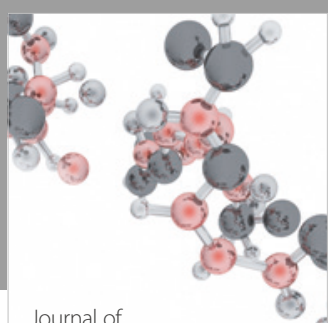

Analytical Methods

in Chemistry

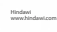

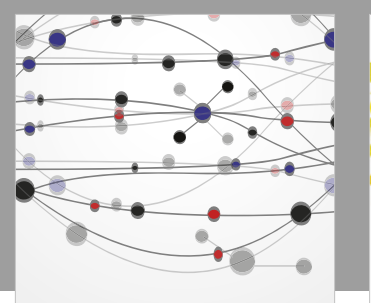

The Scientific World Journal

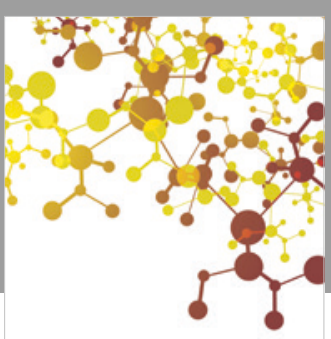

Journal of

Applied Chemistry
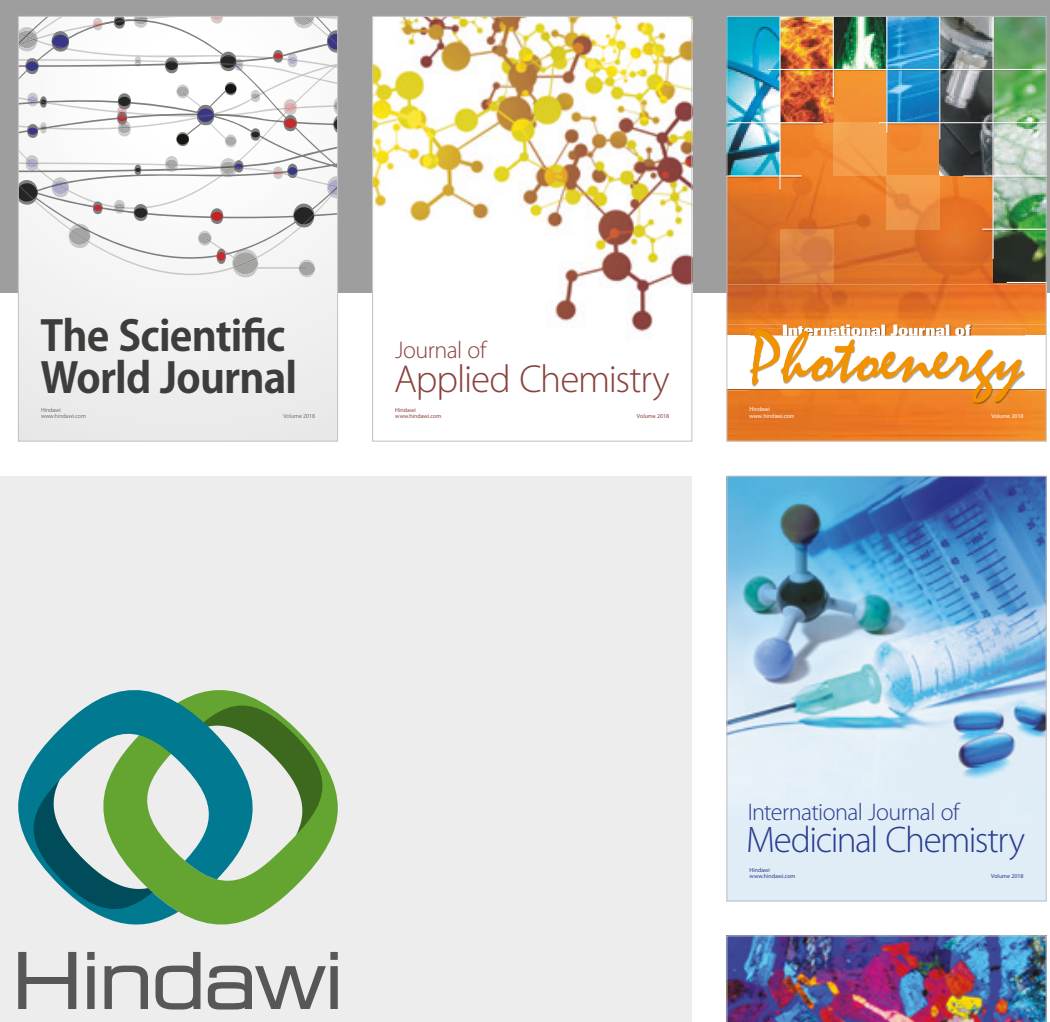

Submit your manuscripts at

www.hindawi.com
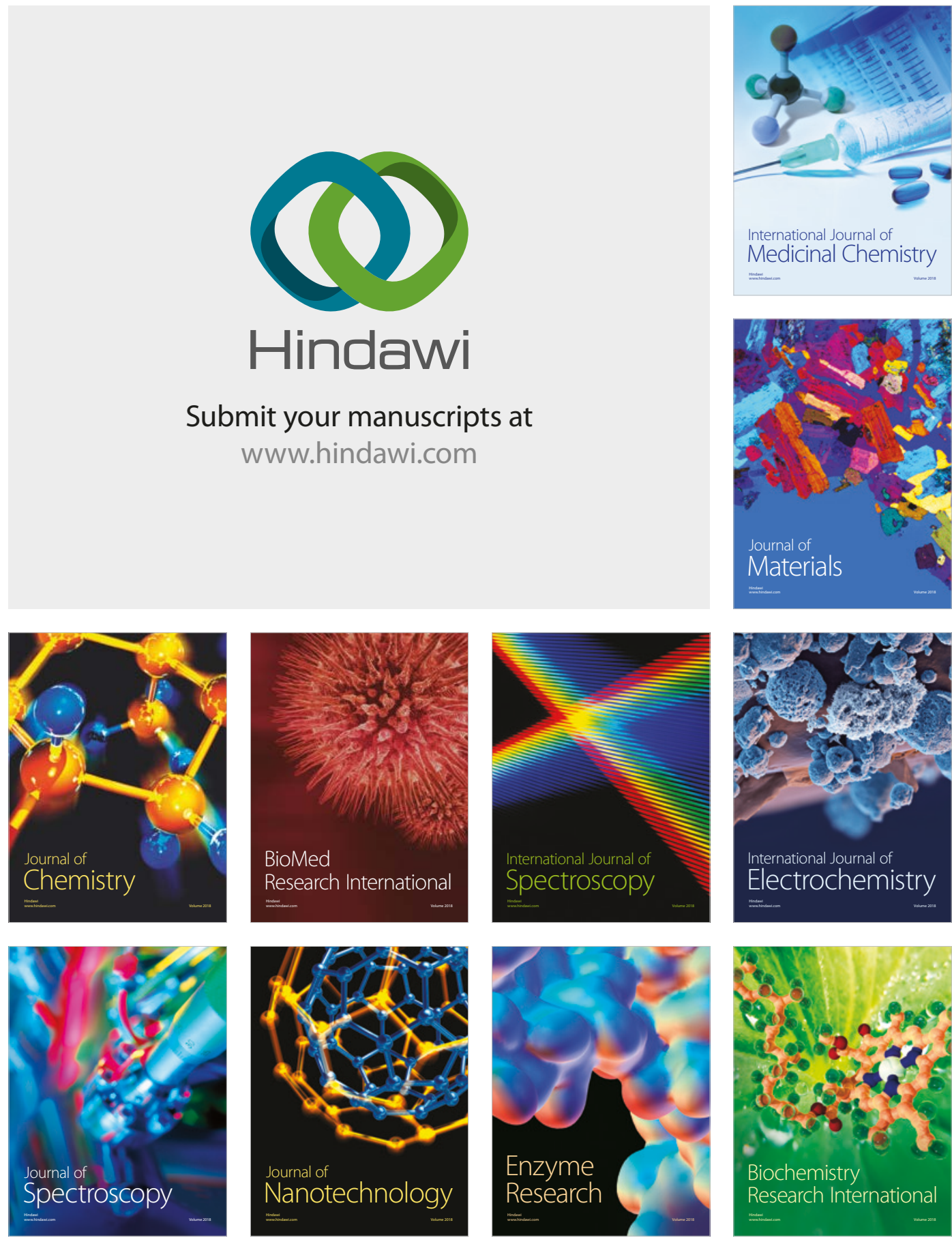
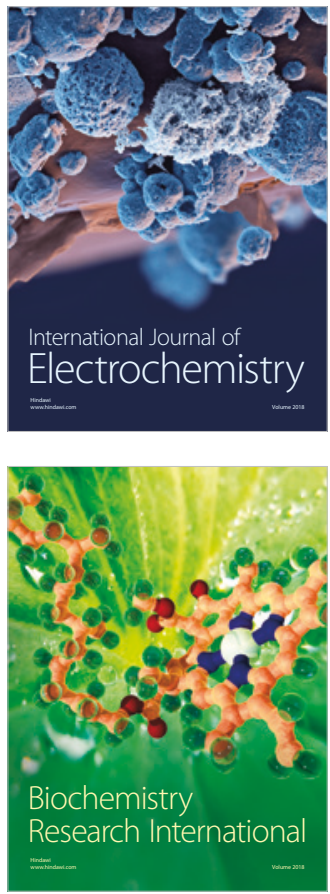